\title{
Capoeira Angola sob a ótica dos estudos da performance e do ritual
}

\section{Cecilia Tamplenizza}

\author{
Universidade Federal da Bahia \\ Salvador, BA, Brasil \\ ceciliatamplenizza@gmail.com \\ orcid.org/0000-0003-1292-262X
}

\section{Edilene Dias Matos}

\author{
Universidade Federal da Bahia \\ Salvador, BA, Brasil \\ edilenediasmatos@gmail.com \\ orcid.org/0000-0002-9474-5374
}

Resumo I O espaço onde acontece a capoeira angola é chamado roda. Os capoeiristas tocam e cantam em círculo, enquanto uma dupla joga ao centro da roda. Para os capoeiristas, a roda ultrapassa os aspectos físicos e estéticos. Faz acontecer e ensina a vida. A partir desse pressuposto, apresenta-se uma reflexão sobre as contribuições que os estudos da performance, do ritual e das poéticas orais podem oferecer ao entendimento da roda de capoeira como ambiente multidimensional.

PALAVRAS-CHAVE: Capoeira Angola. Ritual. Performance. Jogo. Poéticas Orais.
La Capoeira Angola bajo la óptica de los estudios de la performance y del ritual

Resumen | El espacio donde acontece la capoeira angola es Ilamado roda. Los capoeiristas tocan y cantan en círculo, mientras un par juega en el centro de la roda. Para los capoeiristas, la roda ultrapasa los aspectos físicos y estéticos. Hace acontecer y enseña la vida. A partir de ese presupuesto, se hace una reflexión sobre las contribuciones que los estudios de la performance, del ritual y de las poéticas orales pueden ofrecer al entendimiento de la roda de capoeira como ambiente multidimensional.

PALABRAS CLAVE: Capoeira Angola. Ritual. Performance. Juego. Poéticas Orales.

\section{Capoeira Angola from the perspective of performance and ritual studies}

Abstract | The site where the Angola Capoeira ritual takes place is called roda. Capoeiristas play and sing in a circle, while a pair plays in the center of it. For capoeiristas, the roda goes beyond physical and aesthetic aspects; it teaches life and makes it happen. Based on this hypothesis, a reflection is presented on the contributions that studies of performance, ritual, and oral poetics can offer to the understanding of capoeira as a multidimensional environment.

KEYWORDS: Angola Capoeira. Ritual. Performance. Game. Oral poetics

Submetido em: 29/07/2020

Aceito em: 17/09/2020

Publicado em: 09/11/2020 


\section{Introdução}

A roda de capoeira angola é um espaço desenhado e delimitado pelos próprios capoeiristas quando, com seus corpos, se dispõem em círculo para dar forma à performance, ao ritual, ao jogo de capoeira. Esse artigo faz uma reflexão sobre a roda como um ambiente multidimensional. Ideia que tem sido construída ao longo de uma pesquisa etnográfica participativa junto ao Grupo de Capoeira Angola Pelourinho, GCAP, em Salvador/Bahia. A etnografia é aqui entendida como uma prática de cunho interpretativo na medida em que concebe tanto o trabalho de campo (jogo da capoeira) quanto sua reverberação em forma de texto escrito como construções narrativas ${ }^{1}$. Uma performance antropológica, fruto das relações tecidas entre os pesquisadores e os membros do grupo pesquisado². Desde a perspectiva etnográfica, a associação dos conceitos performance, ritual e jogo ${ }^{3}$, adotada nesse artigo para falar da roda, é um ato de tradução (BHABHA, 1998) ou de comparação (SAHLINS, 2018). Uma estratégia para que os não capoeiristas possam compreender a complexidade do lugar por excelência da capoeira angola, a roda. Um espaço, mas também um organismo, ambiguo, que possui múltiplas faces. A experiência etnográfica é um método fundamental, que, no caso, permite, na confrontação com os capoeiristas, realçar um ponto de vista não institucional sobre a capoeira angola. Um ponto de vista que surge do encontro dos estudos acadêmicos com os saberes do grupo. Uma riqueza dinâmica que se adapta no tempo assumindo fazeres e significados diversos, ligados à prática cotidiana de seus intérpretes.

\section{A capoeira angola}

De início, cabe explicar o que se entende por capoeira angola, pois a capoeira é representada por múltiplas vertentes e exponentes nem sempre afins. A capoeira angola é aqui entendida à luz de uma experiência etnográfica participativa, entre os anos de 2010 e 2020, junto ao Grupo de Capoeira Angola Pelourinho, GCAP, que tem sede no Forte da Capoeira em Salvador. Cabe lembrar que a composição do GCAP e suas formas de pensar e fazer não são estáticas. Durante os citados dez anos de pesquisa, houve muitas mudanças na conformação do grupo, seja no que diz respeito a sede em Salvador, nos núcleos de outras cidades, ou ainda em outros gupos orientados. Além disso, muitos dos atuais capoeiristas, que não são mais membros do grupo, treinaram no GCAP em períodos diversos. O único membro que acompanhou toda a trajetória do grupo é exatamente o seu fundador, Mestre

1 Em suas pesquisas, Clifford Geertz desconstrói o mito do pesquisador imparcial como observador objetivo da realidade, como um espelho capaz de refletir por meio da escrita etnográfica as realidades culturais que se Ihe apresentam externamente. Segundo Geertz (1974), ao contrário, a diversidade pode ser apreendida somente como parte do universo cultural do próprio antropólogo. Desse ponto de vista, o pesquisador não descobre uma realidade externa a ele, mas participa da construção dessa realidade em sua própria experiência. O trabalho de Geertz, influenciado pela filosofia de Paul Ricoeur que, nos primeiros anos de 1970, era seu colega de universidade em Chicago, considera a cultura como um texto e o trabalho etnográfico como uma leitura desse texto, uma interpretação. Sobre a obra de Clifford Geertz, além do célebre texto A interpretação das culturas (GEERTZ, 2008), baseia-se na leitura de outros dos seus artigos (GEERTZ, 1974, 1988, 1995, 2000) e no estudo da obra de Malighetti $(2007,2008)$.

${ }^{2}$ No caso específico, os encontros com o GCAP entre 2010 e 2020

${ }^{3}$ Do ponto de vista teórico, tratamos dos conceitos de performance e ritual a partir de dois pontos de vistas: as pesquisas de Victor Turner e Richard Schechner sobre teatro e antropologia, e as pesquisas sobre poéticas orais e performance de Paul Zumthor. O conceito de jogo retoma as pesquisas de Johan Huizinga e do filósofo Hans-Georg Gadamer. 
Moraes. A convivência e prática da capoeira angola no GCAP é e foi referência para muitos dos atuais grupos de capoeira angola . Porém, o que fica claro na convivência com o GCAP e com Mestre Moraes é a falta de identificação com grande parte desses grupos, distinção que se torna um dos pontos principais do trabalho do GCAP com relação ao ensino e à divulgação da capoeira angola ${ }^{4}$. Porém, o que fica claro na convivência com o GCAP e com Mestre Moraes é a falta de identificação com grande parte desses grupos, distinção que se torna um dos pontos principais do trabalho do GCAP com relação ao ensino e à divulgação da capoeira angola.

Essas observações são importantes na medida que os argumentos desenvolvidos, nesse artigo, são baseados em uma pesquisa etnográfica restrita a um período de tempo, a um espaço de convivência delimitados, ao conjunto de pessoas envolvidas, com suas diversas formações e proveniências, e às relações tecidas durante esses encontros. Aqui, não propomos uma reflexão sobre o pensamento dos diversos mestres e pesquisadores que têm tratado o tema da capoeira angola aproximando-o aos estudos da performance, mas propomos relacionar as nossas reflexões, inspiradas pelos dados recolhidos no campo, bem como por nossas vivências com a obra de alguns autores dos estudos da performance, do ritual e das poéticas orais. Essa escolha se dá pela singularidade como o GCAP vem recriando e reinterpretando a tradição da capoeira angola, seja quanto sua organização ou sua concepção ${ }^{5}$.

O GCAP foi fundado no Rio de Janeiro, em 1980, pelo baiano Pedro Moraes Trindade, Mestre Moraes, originário de Praia Grande na Ilha de Maré. O nome Grupo de Capoeira Angoal Pelourinho é um homenagem ao bairro Pelourinho, no centro de Salvador, onde tinha sede o Centro Esportivo de Capoeira Angola de mestre Pastinha. Ali, Moraes conheceu a capoeira angola.

Após uma estadia que ultrappasou uma década, transcorria o ano de 1980, quando por iniciativa do mestre Moraes, foi fundado no Rio de Janeiro o Grupo de Capoeira Angola Pelourinho. Quando retornou a Bahia, em 1982, mestre Moraes efetuou a transferência da sede do mencionado grupo, para radicá-lo definitivamente no estado [...] (MOURA, 2016, p. 21).

Em Salvador, o GCAP se empenhou em envolver os mestres que não ensinavam mais capoeira, convidando-os a falar e mostrar sua arte durante eventos no Forte Santo Antônio Além do Carmo, onde estabeleceu sua sede e em outros centros culturais e instituições. Grandes aliados neste projeto foram os mestres João Pequeno, o primeiro capoeirista a ocupar uma sala do Forte Santo Antônio após o falecimento do Mestre Pastinha, e João Grande que foi convidado para voltar a

\footnotetext{
${ }^{4}$ Não cabe nesse artigo traçar a trajetória do GCAP, uma história rica de encontros e desencontros, não apenas no Rio de Janeiro e Salvador, mas também em outras cidades do Brasil, como por exemplo, Belo Horizonte, Brasília, São Paulo, São Luiz de Paratinga, e fora do Brasil, nos Estados Unidos, no Japão, na França. Para conhecer mais sobre essa história traçada em dois momentos e sob duas perspectivas diferentes ver Araújo (2004) e Tamplenizza (2017).

${ }^{5}$ Ao tratar de uma arte afrodescendente a tradição deve ser vista fora do tradicionalismo, mas inscrita na ancestralidade, que segundo Muniz Sodré (2017), "representa um momento de autonomia grupal enquanto memória continuada e vigilante de um conjunto de regras e de personagens historicamente afinados com uma maneira peculiar de ordenamento do real".
} 
ministrar aulas de capoeira no espaço do GCAP. Entrevistado sobre sua história, Mestre João Grande relembra assim aquela época:

Na época em que eu trabalhava no posto de gasolina a capoeira angola estava baixo, caída. Fiquei cinco anos sem fazer capoeira angola. Não tinha como fazer? Não tinha. Trabalhando muito. Capoeira angola caiu. Só estava por cima a Regional. Capoeira angola só tinha João Pequeno no Forte Santo Antônio. Cobrinha Verde tinha falecido. Mestre Pastinha estava doente. Valdemar só fazia berimbau. Ninguém jogava capoeira mais. [...] Eu estava me sentindo mal. Só fazia show, batia maculelê, puxava rede na Moenda, mas capoeira que é bom não jogava. Quando Moraes fez o encontro e me chamou eu voltei pra capoeira Angola e voltou todo mundo. Voltou Valdemar, finado Zacarias, finado Bobó. Todo mundo voltou pra capoeira angola. Moraes e Cobrinha foram no posto de gasolina me chamar, eu estava na Moenda. Me deram um salário pra eu vir pro GCAP. Deixei a Moenda e passei três anos trabalhando com o GCAP. Ensinando todo mundo lá. Depois de três anos não quis mais ficar lá. Fui trabalhar na Moenda de novo (BARROS, 2010, p. 201).

Segundo Mestre Jair Moura, o trabalho do GCAP e seus aliados nos anos de 1980 foi a mola propulsora de um movimento renascentista da capoeira angola, que influenciou decisivamente a implantação da sua feição hodierna (MOURA, 2016).

O objetivo do GCAP é levar adiante um processo de resistência cultural, liderado por Mestre Moraes, que foi iniciado pelos Mestres João Pequeno e João Grande, alunos de Mestre Pastinha, tendo passado por outros mestres que conheceu em juventude ${ }^{6}$. A essa corrente liga-se a questão de uma ancestralidade ${ }^{7}$, que considera a capoeira como uma arte, um sistema de educação sociopolítica e uma forma de vida. Uma arte praticada pelos trabalhadores afrodescendentes no Brasil, por isso chamada de angola. Segundo as palavras do Mestre Pastinha: "Angola, capoeira mãe. Mandinga de escravo em ânsia de liberdade, seu princípio não tem método e seu fim é inconcebível ao mais sábio capoeirista" (PIRES, 2002, p. 64).

Neste sentido, o GCAP representa uma tradição que tem uma visão sociopolítica da capoeira, definida por Moraes como "um instrumento de luta do proletariado" e um meio orgânico para a análise e a ação sociopolítica da sociedade. Na trajetória do grupo ressaltam tentativas de inovação com o intuito de traduzir para as novas gerações e levar adiante as ideias dos mestres mais antigos, não poupando esforços para pensar a capoeira angola não somente como prática esportiva, mas com um olhar voltado para sua complexidade e seu poder educativo.

Hoje, considerando que muitas pesquisas de cunho descritivo sobre a ca-

\footnotetext{
${ }^{6}$ Segundo Moraes, em entrevista cedida à Cecilia Tamplenizza (06 jan 2015, Salvador-Bahia), ele aprendeu capoeira tendo como referência tanto os Mestres João Pequeno e João Grande na CECA, Centro Esportivo de Capoeira Angola, liderado por Mestre Pastinha, quanto, num momento anterior, alguns mestres "orgânicos" do seu bairro, entre os quais Tonho de Hilda.

7 Por "ancestralidade", o GCAP entende uma ligação pessoal e grupal entre o passado, o presente e o futuro, marcada por uma cosmovisão afrodescendente. Esse assunto merece outro espaço para ser tratado, deixamos aqui a reflexão de Muniz Sodré (2017) como referência: "Diferente do tempo histórico, a temporalidade em que se inscreve o destino é própria da ancestralidade, isto é, da vigência ética do discurso de fundação do grupo, em que se entrelaçam origem e fim". Para saber mais sobre a ideia de ancestralidade para o GCAP ver Tamplenizza (2017).
} 
poeira já foram publicadas, a definição da capoeira angola pode ser tomada até como um caminho banal, pois que aquilo que é visto na capoeira - o jogo, os movimentos, suas regras, os golpes, os instrumentos, os toques, etc... - incorre no aplainamento de suas múltiplas identidades. Sua riqueza está na capacidade de se adaptar em tempos diferentes, assumir formas e significados diversos, ligados à prática cotidiana de seus intérpretes.

Para o Mestre, a complexidade da capoeira angola dificulta-lhe uma definição: "Ela é tudo que a boca come". "Ela é cheia de malícia, é artimanha, tem possibilidade para tudo que pensar de bom na vida". Na belíssima interpretação das palavras do mestre Pastinha, feita pelo Dr. Decânio, "os múltiplos aspectos da capoeira (angola) se manifestam consoante o contexto, como a água que toma a forma do vaso". O Mestre Pastinha disse que "a capoeira é espiritualizada no eu de cada qual"8. (TRINDADE, 2010)

Ao se buscar rapidamente uma definição para capoeira angola é comum ouvir que a capoeira é parecida com uma dança ou uma luta. Para alguns capoeiristas, a dança faz parte da luta e vice-versa. Mas essas definições deixam de lado muitos outros aspectos constitutivos da capoeira como, por exemplo, a espiritualidade e a música, que é executada e criada pelos mesmos capoeiristas, "dançarinos" e "lutadores". Assim, outras palavras como espectáculo, arte e ritual se inserem nessa narrativa.

Nenhuma dessas referidas definições satisfaz plenamente a complexidade cultural que apresenta a roda de capoeira, por isso muitas vezes elas se cruzam, tentando sublinhar os diversos aspectos da capoeira. A definição no portal do IPHAN Instituto do Patrimônio Histórico e Artístico Nacional exemplifica essa dificuldade, ao citar algumas das diversas faces que compõem a roda:

A Roda de capoeira é um elemento estruturante de uma manifestação cultural, espaço e tempo, onde se expressam simultaneamente o canto, o toque dos instrumentos, a dança, os golpes, o jogo, a brincadeira, os símbolos e rituais de herança africana - notadamente banto - recriados no Brasil. Profundamente ritualizada, a roda de capoeira congrega cantigas e movimentos que expressam uma visão de mundo, uma hierarquia e um código de ética que são compartilhados pelo grupo. [...] Hoje, é um dos maiores símbolos da identidade brasileira e está presente em todo território nacional, além de praticada em mais de 160 países, em todos os continentes ${ }^{9}$ (itálico nosso).

Para entender como a capoeira angola é desenvolvida no GCAP é necessário atrelar o ritual da roda à complexa herança africana no Brasil, conforme explica Mestre Moraes, a uma compreensão holística do ritual e a uma dimensão ritual da dança, da música e do jogo10. "O ritual é o lugar próprio à plena expressão e expan-

8 TRINDADE Pedro Moraes. Mestre Pastinha o filósofo da capoeira. 5 abr. 2010. Disponível em: <mestremoraes-GCAP.blogspot.com.br/2010_04_01_archive.html>. Acesso em: 09 abr. 2020.

9 Disponível em: < portal.iphan.gov.br/pagina/detalhes/66>. Acesso em: 09 abr. 2020.

${ }^{10}$ Esse tema certamente merece uma discussão mais ampla que nos propomos a escrever no futuro. Algumas reflexões sobre esse tema se encontram em Tamplenizza (2017). 
são do corpo" (SODRÉ, 2019, p. 83).

À luz dessas considerações, nos propomos agora refletir sobre como os estudos da performance, do ritual e das poéticas orais podem oferecer contribuições para o entendimento da roda de capoeira como esse ambiente holístico, multidimensional.

\section{O conceito de performance aplicado à roda}

O conceito de performance aqui adotado faz referência às pesquisas dos antropólogos Victor Turner e Richard Schechner e suas interligações com os estudos sobre ritual, jogo e dramatização. Ao tratar do teatro desde uma perspectiva antropológica, os dois pesquisadores utilizaram o conceito de performance para incluir ações teatrais não ocidentais, que não eram bem definidas com o termo "teatro ${ }^{11 " .}$ Na perspectiva dos estudos da performance, o teatro não apenas representa, mas permite viver. Problematizar o teatro como performance tem o objetivo de aproximar a distância entre a vida e a arte.

Da mesma maneira, ao falar de capoeira angola por um viés antropológico, foi necessário o questionamento de conceitos que pudessem expressar a complexidade dessa arte de difícil definição, pois ao mesmo tempo que possui elementos semelhantes a outras artes e rituais, ela é absolutamente peculiar. Uma roda de capoeira pode ser entendida como arte, no sentido de criação contínua, pode ser vista como um espetáculo, na medida em que se dá na presença de atores/espectadores. No entanto, uma de suas características mais interessantes é a de estar situada em um entre-lugar, de suspensão entre as margens da produção estética e de instâncias antropológicas ligadas à urgência de conectar homens com outros homens. É aqui que o conceito de performance se torna útil para a compreensão da roda de capoeira angola.

Performance é aqui entendida como uma prática corpórea necessária para uma redefinição crítica da realidade. Um evento fora do cotidiano que, de alguma maneira, se diferencia da vida de todos os dias. Diferentemente do teatro onde a cada temporada são produzidas diversas obras, a capoeira angola é um espetáculo que se repete cada vez igual e diferente.

As atividades do GCAP são semanais. Durante o período de nossa vivência, havia entre dois e três treinos semanais e uma roda ${ }^{12}$. A constância e a repetitividade de treinos podem transformar as atividades do grupo em rotina. $O$ ato de repetir faz parte do aprendizado da capoeira e é parte constitutiva de seus aspectos rituais, dos quais falaremos um pouco mais adiante. No ato de repetir, o corpo aprende a transformar as novidades em novas convicções, a tornar o inusual em cotidiano, em rotina, um processo que foi chamado por Max Weber (2000, p. 161) de rotinização.

Eventos especiais são criados com o propósito de iluminar e de intensificar a vida de todos os dias. Apesar disso, é comum que as pessoas tenham experiências

${ }^{11}$ A palavra grega ' $\theta \varepsilon ́ \alpha \tau \rho o v '$ significa literalmente "lugar onde se vai para ver", onde quem vê/o público, o que se vê/o atuante e o imaginado/o texto são dramatizados.

${ }^{12} \mathrm{~A}$ quantidade de treinos e rodas pode variar dependendo da época. 
ordinárias durante eventos especiais e que as experiências extraordinárias surjam do fluxo da vida cotidiana. A vida pode assim ser compreendida a partir de reflexões e intuições levantadas durante esses eventos especiais. Os capoeiristas entendem e falam de suas vidas a partir das experiências especiais da capoeira. No GCAP, Mestre Moraes fala que a roda é um complexo micro mundo, enquanto a vida de todos os dias pode ser vista como um macro mundo. A roda é projetada para excitar e estimular, e, portanto, tende a gerar experiências mais salientes e estimular mais memórias do que eventos de todos os dias. Para um capoeirista do GCAP, essas emoções e memórias devem animar a vida cotidiana novamente, cobrando das rotinas comuns traços das experiências extraordinárias da roda.

Em entrevista, o contramestre David Fonseca comentou: "nós capoeiristas procuramos levar essa questão do ritmo para nosso dia a dia. Entender nosso ritmo. Procurar equilibrar o nosso ritmo diante das situações, dos contextos de vida. Curar o corpo através do ritmo ${ }^{13 "}$. Associar o ritmo da capoeira à "cura do corpo" é uma maneira de compreender a música atrelada a um aprendizado que não passa somente pelo ouvido, mas que envolve outros sentidos. Não são poucos os casos de capoeiristas que se curaram de problemas motores através do convívio com a capoeira. Baseada no conhecimento corporal, a capoeira pode proporcionar efeitos analgésicos e benefícios cinéticos, além de psicológicos.

Com referência à etimologia, a palavra performance vem do inglês parfourneny depois parfourmen, que deriva do francês antigo parfournir, composto por par \{«completamente») e foumir («fornire»). Segundo Victor Turner (1986, p. 176), a palavra performance refere-se a uma ação processual de «cumprir» ou «completar». To perform é levar até o fim um processo que pode ser mais ou menos complexo, bem mais que cumprir uma única ação. Nesse processo, a performance e o conhecimento daquilo que se transmite estão ligados. A performance, de qualquer jeito, modifica o conhecimento. Ela não é simplesmente um meio de comunicação: comunicando ela o marca (ZUMTHOR, 2007, p. 32). Ainda com Paul Zumthor (2010, p. 166): "Performance implica competência. Além de um saber-fazer e de um saber-dizer, a performance manifesta um saber-ser no tempo, no espaço. O que quer que, por meios linguisticos, o texto dito ou cantado evoque, a performance lhe impõe um referente global que é da ordem do corpo".

A performance da capoeira angola põe em presença diversos atores: os capoeiristas, o público. Os capoeiristas adquirem diferentes habilidades conforme o passar do tempo, envolvendo-se mais com o grupo, aprendendo a assumir diferentes lugares na roda. No início, as categorias do capoeirista e do público se assemeIham. Mesmo sentado na roda, o capoeirista iniciante não tem capacidade de jogar, tocar, ou gerir o ritual. Ele canta, observa e participa como um espectador. Assim, fora do espaço circular da roda, pode acontecer que o público, emocionado, cante junto aos capoeiristas. Através do canto, o público também participa, somando as próprias energias àquelas da roda. Como o público, o capoeirista iniciante, que ainda não tem intimidade com a capoeira, com o fazer e com o pensamento do grupo,

${ }^{13}$ Entrevista David Fonseca, 13 set. 2014, Salvador-Bahia. 
se insere na roda através do canto, pois através da vocalidade o espaço da roda se enche de energia.

\begin{abstract}
Quando designamos a operação do uso da voz de vocalidade, estamos nos referindo a um espaço de produção de signos extremamente complexo, e isto porque tais signos são, ao mesmo tempo, mudos, sonoros, audíveis e inaudíveis, convergindo todos eles para uma espécie de sonoridade corporal, que caracteriza a performance vocal, que não é só som, mas envolve corpo e voz - corpo e voz intimamente entrelaçados de forma que o que não é sonoro se sonoriza, e o que não é visual adquire uma espécie de potencialidade sonora, fazendo da vocalidade uma espécie de cena teatral complexa, feita de signos verbi-voco-visuais (MATOS, 2018, p. 85).
\end{abstract}

No GCAP, se diz que a roda é um espaço onde todos participam ativamente, seja no trabalho da produção de energia, seja nos benefícios que são por ela proporcionados. Mesmo que um capoeirista não saiba tocar, entrar na roda somente para jogar e ir embora logo em seguida é uma atitude não compatível com a harmonia do grupo e e tal comportamento passa a ser considerado egoísta. O mínimo que um capoeirista deve fazer é responder ao coro, no tempo, com vontade e voz alta, durante todo o desenrolar da roda. Em seus manuscritos, Mestre Pastinha se queixava: "Amigos porque não cantam? A capoeira só é bonita jogando, cantando, e só perdeu a beleza porque não canta" (DECÂNIO, 1997, p. 34).

A beleza não deve ser entendida como algo puramente estético, mas algo diretamente ligado à produção de energia. Se os capoeiristas não respondem ao coro, aqueles que estão jogando no centro da roda não conseguirão "derreter". Este derreter, tão difícil de acontecer, pode ser interpretado como a beleza perdida ao qual faz referência Mestre Pastinha, que continua: "É dever de todos capoeiristas, não é defeito não saber cantar; mas é defeito não saber responder, pelo meno o coro. É probido na bateria pessoas que não respondem ao coro" (DECÂNIO, 1997, p. 35). Por meio do canto, todos podem integrar-se à roda com vontade, procurando um caminho de alegria.

Com o tempo, os capoeiristas aprendem a tocar, a jogar, a coordenar, a organizar as atividades da roda. Aprendem a gerir os meios que a performance põe em jogo, a voz, o gesto, a mediação, o "texto em presença" (ZUMTHOR, 2010, p. 166167; FERREIRA, 2007, p. 143). A cada roda do GCAP, textos poéticos formados por cantigas, textos musicais feitos de sons e ritmos e textos corpóreos desenhados por movimentos e relações são interpretados, re-interpretados e improvisados. Não são textos soltos, mas variações, elementos fundamentais da identidade do grupo. Para estudá-los é fundamental atrelar sua compreensão ao contexto performativo, comunitário, à dimensão iminente, corporal e relacional da roda.

"Sendo a roda de capoeira o nosso bem supremo", diz Olujimi ${ }^{14}$, "os alunos devem evitar assumir posições sem ter condição de mantê-las, para facilitar a produção de energia. Em colaboração com os alunos, continua Olujimi, o mestre é "o

${ }^{14}$ Entrevista Olujimi Trindade 9 set. 2014, Salvador-Bahia. 
principal responsável pela manutenção da roda de capoeira, desde o ritmo, o jogo, todos os elementos que envolvem a capoeira angola". O mestre, segundo Olujimi,

é a pessoa que deverá em toda situação reger essa bateria, mas no caso da capoeira angola ele não é aquele maestro que vai estar com uma baqueta na frente dizendo o que você vai fazer, e aí vem a questão do sentimento. É você que vai decidir o que vai fazer naquele momento, sendo que essa decisão é uma decisão que tem uma rédia, é uma decisão que você não pode tomar simplesmente porque você acha que deve fazer aquilo. Tudo aquilo que você teve como decisão tem um principio tem um fundamento e em um espaço muito curto de tempo isso deve ser pensado e executado ${ }^{15}$.

Esse fundamento transmitido no GCAP é de difícil compreensão para muitos que estão acostumados a viver a roda somente como um ritual de união, participação e ação. Não poucas vezes, são ouvidos comentários de pessoas queixosas por não terem participado da bateria, ou de alunos iniciantes, atribuindo o fato à vaidade do grupo. A nosso ver, essa leitura não coincide com a proposta do GCAP mas, pelo contrário, expressa uma questão fundamental para a capoeira. O aprendizado não é alcançado somente por aquilo que se faz, mas, com a mesma intensidade, por aquilo que se poderia fazer mas não se faz. Deixar de participar, reconhecer-se pelas capacidades adquiridas até então, é outra fase do aprendizado.

\section{A roda como um ritual}

Outra dimensão da roda é aquela de viés ritualístico. Desde essa perspectiva, a roda pode ser entendida como uma instituição, ou melhor, uma assembleia. O conceito de ritual nos aproxima da roda como um evento que apresenta e desvela aos capoeiristas o desenrolar das relações sociais. Ao par de outras reuniões que acontecem em círculo, a roda pode ser um lugar de tomada de decisões, uma maneira de organizar o "mundo afora"16, a sociedade, dotando de significado as experiências reais e imaginadas que ali acontecem. As questões ali debatidas são discutidas com uma linguagem diferente da verbal. Uma linguagem que se expressa através do corpo-voz-comunidade e que utiliza formas de expressão poética, vocal, musical, corporal e ritual.

Desde a perspectiva da repetição, elemento fundamental do ritual, a roda é um palco perfeito, que mostra as reações dos capoeiristas e sua profundidade de interiorização da capoeira. Saber controlar as reações nas situações mais complicadas, "de aperto", exige um conhecimento profundo da movimentação de capoeira e envolvimento com todos os elementos do ritual. Mas, ao mesmo tempo em que é fácil observar os outros, é difícil conseguir enxergar-se a si mesmo, "dói" no sentido de que é necessário aceitar-se como aquilo que não gostamos para enfrentarmos

\footnotetext{
${ }^{15}$ Ibidem.

16 Para tentar traduzir as experiências cotidianas no GCAP, recorremos, ao longo do texto, a citações (entre "aspas") e metáforas, assim como, entrevistas e anotações de conversas informais. Essas técnicas, próprias do trabalho etnográfico, foram muito úteis para a construção da escrita. Porém, sua utilização não foi fácil, já que a linguagem própria do contexto vocal aparece como mais romanceada no texto escrito, pois, quem lê não tem à sua frente a pessoa falando, apresentando, com as marcas, as posturas e expressões de seu corpo sua personalidade e história.
} 
mudanças e seguir adiante no aprendizado. Esta dificuldade parece ser um dos maiores entraves no aprendizado da capoeira e pode levar as pessoas treinar por anos sem obter grandes transformações. Está também ligada a capacidade de interpretar a performance como evento capaz de proporcionar experiências extraordinárias.

O aprendizado no GCAP acontece por transmissão oral e presencial em uma dimensão ritual, seja nos treinos, seja nas rodas. Assim como a vivemos, a prática da capoeira é intertextual, fundamentada no constante diálogo entre a fugacidade do enredo corporal, oral, ritual e a repetitividade da trama midiática gravada em livros, áudios e vídeos. É reconhecível uma tradição poética da capoeira angola que envolve o corpo-voz dos capoeiristas. Uma corporalidade que inclui a voz, mesmo que impalpável e imanente. As palavras, os sons e versos, após pronunciados, deixam rastros, que continuam ecoando e vibrando no corpo+mente, parte integrante da ação corporal.

Mas, o ritual, assembleia, roda, longe de ser apenas uma mise-en-scène, uma representação, um espaço ou tabuleiro de jogo, ensina que existe uma verdade dada pelos acontecimentos que ali ocorrem. Uma realidade atemporal que conduz os capoeiristas a reinterpretar o aprendizado dos treinos, as lembranças do que é vivido por eles nas ruas, no trabalho, no cotidiano. Segundo o que é ensinado no GCAP, esta prática é atemporal porque na ilusão, ou na esperança, de poder repetir movimentos, ouvir e levar adiante ritmos, cantos e mitos ancestrais é criada uma continuidade entre as vidas dos capoeiristas do presente e do passado. Repetindo e criando na roda, o passado ancestral se torna presente, existente.

Essa atitude propõe um aprendizado contínuo e é entendida pelo grupo como uma resistência, por meio da qual, os capoeiristas procuram se libertar de suas vidas, esquecendo o cansaço, as dificuldades econômicas, o engarrafamento, a violência nas ruas, as dependências, as doenças... A roda de capoeira do GCAP pode ser entendida como uma communitas ${ }^{17}$ no sentido turneriano.

A "communitas" irrompe nos interstícios da estrutura, na limina-
ridade; nas bordas da estrutura, na marginalidade; e por baixo da
estrutura, na inferioridade. Em quase toda parte a "communi-
tas" é considerada sagrada ou "santificada", possivelmente por-
que transgride ou anula as normas que governam as relances
estruturadas e institucionalizadas, sendo acompanhada por ex-
periência de um poderío sem precedentes (TURNER, 1974, p. 156).

Ao mesmo tempo que a roda pode ser entendida como uma representação teórica da ação da sociedade, o que a movimenta é sua liminaridade, um estado em

\footnotetext{
${ }^{17}$ Segundo Turner (1987, p. 84): "O individualismo extremo apenas compreende parte do homem. O coletivismo extremo apenas compreende o homem como parte. Communitas é a lei implícita da completude (wholeness) advinda de relações entre totalidades". Crítica ao conceito de communitas usado por Turner: Segundo De Matteis (1993, p. 25, trad. autor) Turner toma o conceito de comunidade em referência a Martin Buber, não como lado a lado, ou além, de uma multidão de pessoas, mas como sendo um com o outro. Mesmo que a multidão se mova em direção a um objetivo comum, ela "experimenta por toda parte um dirigir-se para um dinâmico estar na frente dos outros, um fluir do Eu para o Você. A comunidade é aonde se faz evento a comunidade" (Paul Goodman, Growing Up Absurd and The Community of Scholars, p. 207-225). Para Turner, assim, a communitas adquire um valor somente positivo e é analisada sozinha: "identificado um processo, uma dinâmica, e, dentro destes, o lugar da comunidade, é o resultado a ser verificado, comparado com as mais diversas situações" (TURNER, 1993, p. 26, trad. nossa)
} 
que as hierarquias e as diferenças da sociedade podem desaparecer. Quando uma roda acontece de uma maneira ótima, o grupo se torna uma continuidade, uma communitas, em que as maneiras de pensar, agir e sentir são desestruturadas: "la liminalità può in parte essere descritta come una fase di riflessione che spezza la crosta del costume e dà via libera alla speculazione ${ }^{18 "}$ (De Matteis em TURNER, 1993, p. 23). A roda como ritual liminar além de desestruturar as experiências, sugere aos capoeiristas outra maneira de ser, proporcionando uma nova estruturação.

A liminaridade pode ser associada, como sugere Carapanzano (2005, p. 375) se referindo ao estudo de Chittick (1989), ao conceito filosófico de "barzakha - o que está situado entre as coisas, entre as bordas, as divisas e os eventos". Metaforizado como o silêncio entre as palavras e aos sonhos. Barzakhi é um conceito utilizado pelo filosofio sufi andaluz Ibn al-'Arabi (1165-1240), segundo o qual a imaginação (alkhayal) é um termo intermediário que, em alguns momentos, parece estar entre o mundo espiritual e o material, em outros, entre o ser e o nada, como algo equivalente à existência.

Algo que separa [fâsil] duas outras coisas, sem nunca pender para um lado [mutatarrif], como, por exemplo, a linha que separa a sombra da luz do sol... O barzakhi é algo que separa o conhecido do desconhecido, o existente do inexistente, o negado do afirmado, o inteligível do ininteligível (CHITTICK, 1989, p. 117-18).

Na prática, filosófica e corporal do que está invisível, em constante busca, os membros do GCAP são levados a procurar outras verdades, para a roda e para a vida cotidiana. Mestre Pastinha (DECÂNIO, 1997, p. 67) afirma:

Capoeiristas <se > esclarece, come samo e entra de fato no verdadeiro conhecimento de si mesmo, estudioso e desejoso de conhecer a capoeira. Vem de olho fito para mostrar a verdade de que não foram negados pelos negos iniciadores, em cada nego os gestos de modo diferem, amigos, tem segredo, e é muito confuso, só com tempo.

Como ressalta Decânio em comentário ao texto de Mestre Pastinha, o caminho da capoeira é de autoconhecimento. Assim como um caminho de criação de verdade no âmbito da diversidade.

Se analisada como um ritual, a capoeira tem algumas características próprias dos rituais de inversão e de elevação de status. Na roda, todo mundo pode participar, "capoeirista é também doutor", canta Mestre Pastinha, o que importa não é o status, a hierarquia social, mas o conhecimento de capoeira em que "igualdade e hierarquia são lá misteriosamente a mesma coisa" (TURNER, 1974, p. 219). O advérbio misteriosamente não se refere a algo obscuro que não pode ser compreendido, mas algo para o qual os capoeiristas precisam atentar. Apesar de existir uma hierarquia formal composta por mestre, contramestres, alunos, os princípios que regem a convivência no grupo resultam mais importantes que os cargos.

18 "A liminaridade pode ser descrita como uma fase de reflexão que quebra a "casca" do costume e libera a especulação" (trad. nossa). 
Em 1952, Eunice Catunda já tinha relatado este aspecto, mesmo que tenha tentado associá-lo à sua compreensão de disciplina. Catunda tinha visto a capoeira no barracão de Mestre Waldemar:

O ritual, a tradição a que obedecem os participantes da capoeira, são muito rígidos. O mestre é o conhecedor da tradição. Daí ser ele, também a autoridade máxima. (...) Essa autoridade do Mestre é uma das coisas mais admiráveis e comoventes que tenho visto. O respeito a ele demostrado pela coletividade, o carinho com que o cercam, fariam inveja a muito regente da música erudita. Prova isto que o espírito de disciplina é mais vivo no povo rude e inculto de nossa terra, quando este se organiza, que entre as camadas superiores, já mais habituadas à organização consequente da própria instrução e do exercício de atividades culturais e que, por isso mesmo, teriam maior obrigação de compreender a necessidade e a importância da disciplina na coletividade. Acontece porém que o Mestre nunca abusa de seus direitos. Não se atribui poderes ditatoriais. Sabe que sua autoridade emana da própria coletividade e comporta-se como parte integrante desta (CATUNDA, 1952, p.17).

No GCAP, os títulos, mestre e contramestre, não são categorias fixas. Sua atribuição depende não somente dos conhecimentos que é preciso ter, mas também do contexto em que o grupo se encontra, da atitude do aluno, entre outros fatores. Idealmente, a hierarquia no GCAP não está relacionada à manutenção de uma casta de privilegiados, ela não é absoluta, mas funcional ao conhecimento e, mais concretamente, ao projeto de preservação da capoeira angola. Mesmo o líder do grupo sabe que não se encontra eternamente no "topo da pirâmide", os alunos vão embora, seguem outros caminhos, contradizem os ensinamentos, chegando até a separar-se e criar novos grupos, dando, assim, metaforicamente, a volta da pirâmide. Por conta de tais considerações, a hierarquia no GCAP deve ser representada por um círculo em lugar de uma pirâmide, o espaço da roda, a assembleia.

Ainda pensando na roda como ritual liminar, que estimula o autoconhecimento, nos parece interessante observar que o tipo de liberdade e conhecimento experimentados não são iguais para todos os capoeiristas. Entre as problemáticas levantadas por Turner sobre rituais de passagem se encontra aquela referente à liberdade liminar (TURNER, 1974, p. 242):

enquanto os indivíduos estruturalmente bem dotados buscam a libertação, os inferiores na estrutura podem procurar, em sua liminaridade, um envolvimento mais profundo numa estrutura que, mesmo sendo apenas fantástica e fictícia, Ihes possibilita entretanto experimentar, por um breve período de tempo legitimada, uma espécie diferente de "libertação" de um diferente tipo de destino.

Ainda continua Turner (1974, p. 242), seja quem procura na liminaridade a libertação, seja um envolvimento mais profundo com a estrutura, tudo isso acaba por reforçar a estrutura social vigente. No caso dos indivíduos estruturalmente bem dotados, a estrutura social é reforçada porque o sistema de posições sociais não é contestado. No segundo caso, "a humildade reforça um orgulho legítimo da 
posição, a pobreza afirma a riqueza e a paciência mantém a virilidade e a saúde". A liberdade que a capoeira proporciona não deve ser atrelada somente à autoconhecimento ou afirmação. Às vezes, o caminho da capoeira pode ser empreendido por necessidade. Quando a capoeira communitas, instrumento de desconstrução, libertação, necessidade e afirmação, dá um retorno para a sociedade, fica evidente que as pessoas estão vinculadas aos seus contextos e condições.

Para compreender o ritual da roda em sua complexidade, é fundamental, então, que este não seja interpretado apenas como communitas. Ao mesmo tempo que a roda, idealmente desestrutura a realidade social, ela pode também ser entendida como sua plena representação, apontando que as relações entre os capoeiristas e suas ações não são livres das determinações sociais. O ritual da roda é assim caracterizado por uma grande ambiguidade. No lado oposto da liminaridade, da liberdade liminar, podem manifestar-se também as hierarquias e "ismos" machismos, racismos, autoritarismos. Tais situações devem ser percebidas, analisadas e trabalhadas pela roda como uma assembleia. Nesse sentido, este movimento ou, como sugere Crapanzano (2005), essa "flutuação entre ideal e real" carateriza o aprendizado ritual da roda e, ao mesmo tempo, a torna um evento de difícil apreensão. Olhar somente para as características ideais da communitas transforma o capoeirista num sujeito desconectado com a realidade. Olhar somente as caraterísticas sociais engana o capoeirista com uma perspectiva limitada, já que a roda é somente uma representação parcial da sociedade, podendo levá-lo a reforçar a estrutura que pretendia transformar.

\section{A roda, um jogo de grupo}

Outra maneira que temos para refletir sobre a roda é na perspectiva do conceito de jogo atrelado à dimensão da performance e do ritual. Se, de um lado, é certo o que afirma Muniz Sodré (1988, p. 15): "O jogo devolve ao indivíduo a disponibilidade mental e física da criança. Jogar - ou brincar - é de algum modo contornar a seriedade do conceito de arte, estabelecido por um sistema neurótico chamado cultura". De outro lado, no GCAP, é muito importante apreender a distinguir o jogo da brincadeira como diversão ou entretenimento. Como lembra Johan Huizinga, o jogo pode ser profundamente sério e é assim, com seriedade, que o GCAP lida com a dimensão lúdica da capoeira.

Escusado seria dizer que a atitude espiritual de um grupo social, ao efetuar e experimentar seus ritos sagrados, é da mais extrema e mais santa gravidade. Mas insistamos uma vez mais: o jogo autêntico e espontâneo também pode ser profundamente sério. $O$ jogador pode entregar-se de corpo e alma ao jogo, e a consciência de tratar-se "apenas" de um jogo pode passar para segundo plano. A alegria que está indissoluvelmente ligada ao jogo pode transformar-se, não só em tensão, mas também em arrebatamento. A frivolidade e o êxtase são os dois pólos que limitam o âmbito do jogo (HUIZINGA, 2000, p. 26).

Ainda, segundo Huizinga (2000, p. 6), a própria existência do jogo confirma a existência de um componente supralógico na natureza humana: "Se brincamos 
e jogamos, e temos consciência disso, é porque somos mais do que simples seres racionais, pois o jogo é irracional." Na capoeira, o jogo não é nem exatamente brincadeira nem seriedade, mas é uma "realidade" intermediária, que inclui a racionalidade e a irracionalidade. Nessa condição, o capoeirista apreende a conviver com a ambiguidade da condição humana. Nesse sentido, citando ainda Huizinga (2000, p. 4), o que está em "jogo" no jogo da capoeira "transcende as necessidades imediatas da vida e confere um sentido." Considerando essa perspectiva, o jogo tem a qualidade de por em diálogo corpos, pensamentos, sentidos e percepções, à procura de uma outra experiência que, por vezes, é associada à ideia de liberdade. A liberdade é, segundo Huizinga, associada à dimensão do prazer, como, por exemplo, as crianças e os animais que brincam porque gostam. Na idade adulta, mesmo que jamais seja imposto ou constitua uma tarefa, o jogo se torna uma necessidade urgente de reencontro com o prazer e com a liberdade. No jogo da capoeira, é possível pensar no capoeirista iniciante como uma criança, assim, quem começa o faz porque gosta; com o tempo e o aprendizado, jogar se torna para a maioria uma necessidade prazerosa. Ainda, para Huizinga, o jogo poder ser considerado uma evasão da vida real, do trabalho, sem perder, por isso, a capacidade de absorver inteiramente o jogador, com seriedade.

O filósofo Hans-Georg Gadamer (1997) alerta que, para compreender o conceito de jogo, é necessário libertá-lo de seu significado subjetivo. Gadamer está interessado na sua correlação com a experiência estética da arte. O jogo não significa, então, comportamento, estado de ânimo ou liberdade de uma subjetividade, que atua no jogo, mas é necessário diferenciar o jogo e o comportamento do jogador:

o jogar preenche a finalidade que tem, quando aquele que joga entra em jogo. Não é a relação que, a partir do jogo, de dentro para fora, aponta para a seriedade, mas é apenas a seriedade que há no jogo que permite que o jogo seja inteiramente um jogo. Quem não leva a serio o jogo é um desmancha-prazeres. O modo de ser do jogo não permite que quem joga se comporte em relação ao jogo como em relação a um objeto, Aquele que joga sabe muito bem o que é o jogo e que o que está fazendo é "apenas um jogo", mas não sabe o que ele "sabe" nisso. [...] A obra de arte tem, antes, o seu verdadeiro ser em se tornar uma experiência que irá transformar aquele que a experimenta. O "sujeito" da experiência da arte, o que fica e persevera, não é a subjetividade de quem a experimenta, mas a própria obra de arte (GADAMER, 1997, p. 175).

Dessa perspectiva, o jogo, dotado de uma natureza própria, independente da consciência daqueles que jogam, tem um poder significante. Através dos jogadores, o jogo ganha uma representação. Assim, continua Gadamer (1997, p. 181), "todo jogar é um ser-jogado. [...] O verdadeiro sujeito do jogo [...] não é o jogador, mas o próprio jogo. É o jogo que mantém o jogador a caminho, que o enreda no jogo, e que o mantém em jogo". As regras e os regulamentos são distintos em cada jogo, impondo uma ou várias tarefas para os homens que jogam. Mas, continua o filósofo, "o verdadeiro fim do jogo não é, de forma alguma, a solução dessas tarefas, mas a regulamentação e a configuração do próprio movimento do jogo" (GADA- 
MER, 1997, p. 183). Segundo Gadamer (2002, p.180), "jogo é, na verdade, um processo dinâmico (cinético) que abraça os jogadores ou o jogador".

Quanto à dimensão ritualística, ao jogar, os capoeiristas encenam uma representação da capoeira, mas isto é apenas um ponto de vista. A capoeira existe independentemente de sua representação na roda, ou, como afirma Mestre Moraes, a capoeira vai além de seus aspectos tangíveis, além do movimento do corpo, "jogar pernas pra cima", o que importa são os elementos impalpáveis. Para facilitar essa compreensão, no GCAP, se aprende que é possível jogar capoeira através das palavras ou de comportamentos cotidianos externos à roda. Segundo afirma Olujimi Trindade, hoje contramestre do grupo:

Mestre Moraes nos ensina que o ser capoeirista vai muito além de jogar perna para cima do tocar o berimbau cantar músicas, ele vai muito mais além disto. Ser capoeirista envolve uma questão que ela é muito subjetiva, que apenas um outro capoeirista vai poder verificar, vai poder sentir. O capoeirista tem um artefato que é muito singular, que é justamente a questão do sentimento. Apenas aquelas pessoas que querem se tornar especialistas daquilo que fazem, ou que se predispõem a fazer, vão poder adquirir este sentimento. Isto não é para qualquer pessoa ${ }^{19}$.

Mestre Moraes costuma propor a seus alunos o uso de uma metáfora para exemplificar como a energia flui na roda. Ele vê os tocadores de todos os instrumentos musicais como "fósforos" e o tocar os instrumentos e o início do canto como o risco desses fósforos, acendendo, assim, as "velas", que são os capoeiristas ao compor o círculo da roda. A energia produzida toma assim o centro da roda enchendo seu espaço e permite às duas velas, que ali estão jogando, derreter uma junto da outra. Continua Moraes:

Logicamente, as duas "velas" que estão mais próximas dos "fósforos" irão receber mais energia que as outras, o que resultará em derretimento e consequente amalgamento capaz de dificultar, para os desentendidos, o que realmente está acontecendo no centro da roda com aquelas duas velas em processo de "derretimento". Os elementos simbólicos da roda de capoeira estão à disposição de qualquer um. O desafio é conseguir transformar esses elementos em energia, de forma a estimular o transe ${ }^{20}$.

Esse derreter é também chamado por Moraes de sentimento. Para se movimentar com sentimento é necessário o estímulo da música e relacionar o som com a interioridade de cada um. A música provoca os capoeiristas que, emocionados, transferem energia uns para os outros. O centro da roda, onde acontece o jogo, é o lugar privilegiado que recebe por todas as direções essa energia capaz de levar ao transe os capoeiristas atentos para ela. No transe, afirma Moraes ${ }^{21}$, o capoeirista sabe o que está fazendo, ele atinge um estado de espirito elevado, que não é o físico, do corpo

\footnotetext{
${ }^{19}$ Entrevista Olujimi Trindade 9 set. 2014, Salvador-Bahia.

20 Trindade, 18 mai. 2009, disponível em <mestremoraes-GCAP.blogspot.com.br/2009/05/roda-de-capoeira-um-espaco-sagrado.html>, consultado em 08 abr. 2020.

${ }^{21}$ Palestra sobre Musicalidade na capoeira, por Mestre Moraes, 31 jul. 2015, Cremona, Italia.
} 
como matéria: "corpo leve é o que sobe, o pesado desce. Então, ele está num estado de espirito de leveza, mas não está possuído".

A música, escreve Blacking (1986, p. 70), possibilita o acesso a um universo de tempo virtual, chamado por Gustav Mahler de outro mundo, ou de outra mente pelos balineses. É neste estado de leveza que o capoeirista se compreende a si mesmo e ao mundo que o rodeia, como que aconselhado pelos seus ancestrais. O jogo de capoeira se torna uma verdadeira fonte de aprendizado e a música começa a significar em termos de experiência humana e de comunicação. Ainda, afirma Moraes:

Se emocionados [os capoeiristas] vão dialogar, vai acontecer um diálogo de corpos. Diferente do fight vai acontecer o struggle. Ai é que esta a questão, esta diferença entre lutar capoeira e dialogar capoeira. A maioria hoje esta lutando capoeira. Ora, para lutar não precisa ser com capoeira. O espaço simbólico não é lugar para luta, africanamente falando, o espaço simbólico da roda é um lugar para diálogo e tomada de decisões em grupo.

O mestre de capoeira sabe tocar e gerar essa energia. Ele ensina a seus alunos o diálogo com a música de maneira a sentir essa estado de leveza, esse outro corpo-tempo-espaço. A música por si não é suficiente para criar esse estado, é necessário treinar muito, isto porque, como afirma Blacking (1986, p. 41): "potrebbero esserci molte interpretazioni strutturali possibili per ogni modello sonoro ed un numero pressoché infinito di reazioni individuali alla sua struttura, in funzione del bagaglio culturale e del momentaneo stato emotivo degli ascoltatori"22. A energia da qual Mestre Moraes fala não acontece automaticamente a cada roda, é algo diferente do comum, difícil de gerir, assim como a communitas de Turner (1974, p. 170), ela é compreendida como uma fase, um momento, não uma condição permanente. No GCAP, os alunos almejam aprender a gerar e manter essa energia peculiar, colaborando uns com os outros no jogo da roda.

\section{Considerações finais}

Refletir sobre a roda a partir dos conceitos performance, ritual e jogo permite evidenciar aspectos complexos da capoeira angola, não apenas como prática mas como um ambiente multi dimensional que proporciona aos capoeiristas estímulos diversos. A proposta do GCAP é ensinar a lidar politicamente com essas diferentes dimensões a partir de um aprendizado corporal e relacional sabendo "que a capoeira pode te levar para cima ou para baixo"23. Por um lado, empreender um caminho de aprendizado, de descobrimento, de flutuação entre ideal e real, sabendo que isto não levará a nenhum fim ou certeza. E, por outro lado, sentir-se alvo das armadilhas do ritual e de sua demasiada humanidade, encontrando-se preso no vazio da vaidade e da ilusão.

\footnotetext{
22 "Pode haver muitas interpretações estruturais possíveis para cada modelo sonoro e um número quase infinito de reações individuais à sua estrutura, dependendo da bagagem cultural e do estado emocional momentâneo de ouvintes" (trad. autor).

${ }^{23}$ Esta frase é muitas vezes citadas por Mestre Moraes que a atribui a Mestre João Grande.
} 


\section{Referências}

ARAÚJO Rosângela Costa. Iê Viva meu Mestre: a capoeira angola da "escola pastiniana" como práxis educativa. Tese (Doutorado) Faculdade de Educação, Universidade de São Paulo, 2004.

BARROS Maurício de Castro. Mestre João Grande: na roda do mundo. Rio de Janeiro: Garamond, 2010.

BHABHA, Homi K. O local da cultura. Belo Horizonte: Editora da UFMG, 1998.

BLACKING John. Come è musicale I'uomo? Milano: Unicopoli, 1986.

CATUNDA Eunice. Capoeira no Terreiro de Mestre Waldemar. Fundamentos - Revista De Cultura Moderna, n. 30, São Paulo, 1952, p. 16-18.

CHITTICK William C. The sufi path of knowledge: Ibn al-'Arabi's metaphysics of the imagination. Albany: State University of New York Press, 1989.

CRAPANZANO Vincent. A cena: lançando sombra sobre o real. Mana [online]. 2005, vol.11, n.2, p.357-383. ISSN 0104-9313. http://dx.doi.org/10.1590/S010493132005000200002 .

CRAPANZANO Vincent. Horizontes imaginativos e o aquém e além. Revista de Antropologia, São Paulo, USP, vol. 48, n. 1, 2005, p. 363-384.

DECANIO Ângelo A. Filho. A herança de Pastinha. Coleção São Salomão, 1997, edição eletrônica, disponível em: <http://www.sementedojogodeangola.org.br/index.php?title=Downloads >, acesso em 20 abr 2020.

FERREIRA Jerusa Pires. O universo conceitual de Paul Zumthor no Brasil. Revista do Instituto de Estudos Brasileiros, n. 45, p. 141-152, 1 set. 2007. Disponível em: https://doi.org/10.11606/issn.2316-901X.v0i45p141-152. Acesso em 17 abr 2020.

GADAMER Hans-Georg. Verdade e Método. Petópolis RJ: Vozes, 1997. GADAMER Hans-Georg. Verdade e Método II. Petrópolis RJ: Vozes, 2002.

GCAP, Grupo de Capoeira Angola Pelourinho. Universo Musical da Capoeira. Salvador-Bahia: Comissão de Documentação e Acervo, 1994.

GEERTZ Clifford. A interpretação das culturas. Rio de Janeiro: LTC, 2008. 
GEERTZ Clifford. Local Knowledge: Further Essays In Interpretive Anthropology. New York: Basic Book, 2000.

GEERTZ Clifford. After de fact: two countries, four decades, one anthropologist. London: Harvard University Press, 1995.

GEERTZ Clifford. Work and Lives. Stanford: Stanford University Press, 1988.

GEERTZ Clifford. From the Native's Point of View: On the Nature of Anthropological Understanding. Bulletin of the American Academy of Arts and Sciences, Vol. 28, n. 1, Oct., 1974, pp. 26-45.

HUIZINGA Johan. Homo Ludens. São Paulo: Editora Perspectiva, 2000.

MATOS Edilene Dias. A voz e suas poéticas. Repertório, Salvador, ano 21 , n. 30, p. 81-99, 2018.

MALIGHETTI Roberto. O Quilombo de Frechal: Identidade e trabalho de campo em uma comunidade brasileira. Brasília: Senado Federal, 2007.

MALIGHETTI Roberto. Clifford Geertz: Il lavoro dell'antropologo. Torino: Utet, 2008.

MOURA Jair. Os precursores do renascimento da capoeiragem angola. Em Capoeira em múltiplos olhares: estudos e pesquisas em jogo. Organizado por Antônio Liberac Cardoso Simões Pires, Franciane Simplicio Figueredo, Paulo Andrade Magalhães Filho, Sara Abreu da Mata Machado. Cruz das Almas: EDUFRB, Belo Horizonte: Fino Traço, 2016.

PIRES Antônio Liberac Cardoso Simões. Bimba, Pastinha e Besouro de Mangangá: Três personagens da capoeira baiana. Tocantins/Goiânia: NEAB/ Grafset, 2002.

SAHLINS Marshall. Esperando Foucault, ainda. São Paulo: Ubu Editora, 2018.

SODRÉ Muniz. Pensar Nagó. Petrópolis, RJ: Vozes, 2017.

SODRÈ Muniz. O terreiro e a cidade: a forma social negro-brasileira. Rio de Janeiro: Vozes, 1988.

TAMPLENIZZA Cecilia. Do canto ao gesto, do corpo ao texto: diálogos com o Grupo de Capoeira Angola Pelourinho. Tese (Doutorado) Pós Cultura, Programa Multidisciplinar em Cultura e Sociedade IHAC/Universidade Federal da Bahia em cotutela com o Programa de Doutorado em Antropologia 
Sociale e Culturale da Università Statale di Milano-Bicocca, 2017.

TURNER Victor. 0 processo ritual: estrutura e anti-estrutura. Petrópolis: Vozes. 1974.

TURNER Victor. Dal rito al teatro. Bologna: Il Mulino, 1986.

TURNER Victor. The Anthropology of Performance. New York: PAJ, 1987.

WEBER Max. Economia E Sociedade: Fundamentos da sociologia compreensiva. Vol.1 Brasília: Editora Universidade de Brasília, 2000.

ZUMTHOR Paul. Performance, recepção e leitura. São Paulo: Cosac Naify, 2007.

ZUMTHOR Paul. Introdução à poesia oral. Belo Horizonte: Editora UFMG, 2010. 